Check for updates

Cite this: RSC Adv., 2019, 9, 37895

\title{
Gravimetric analysis of the autocatalytic growth of copper microparticles in aqueous solution $\uparrow$
}

\author{
Jinuk Byun, ${ }^{a}$ Kwang Hawn Kim, ${ }^{a}$ Byung Keun Kim, ${ }^{a}$ Ji Woong Chang, (D) ${ }^{b}$ \\ Sung Ki Cho (D) *b and Jae Jeong Kim (D)*ac
}

\begin{abstract}
The growth kinetics of copper microparticles was analysed by using the gravimetric method. The copper microparticles were synthesized in aqueous solution containing cupric ion and $\mathrm{HCHO}$ under various conditions (temperature, additive) and the total mass was monitored during the synthesis. The relation between the total mass and time was formularized using heterogeneous and pseudo-first order reaction kinetics of the autocatalytic surface growth of copper with a modification of the Finke-Watzky kinetic model. Fitting of theoretical curves to the experimental results with various temperatures provided the rate constants of the surface growth, and the reaction activation energy was found from the Arrhenius plot to be $105.4 \mathrm{~kJ} \mathrm{~mol}^{-1}$. The obtained value was validated by comparing it with one from copper film growth. Its change was observed with the addition of 2,2'-dipyridyl during synthesis.
\end{abstract}

Received 29th August 2019

Accepted 9th November 2019

DOI: $10.1039 / c 9 r a 06842 b$

rsc.li/rsc-advances

the autocatalytic reaction. Cupric ion $\left(\mathrm{Cu}^{2+}\right)$ can be reduced by formaldehyde as a reducing agent, and reduced $\mathrm{Cu}$ as a reaction product catalyzes the oxidation of formaldehyde. ${ }^{5,6}$ In alkaline solution, formaldehyde is transformed into methylene glycol, and donates electron for the reduction (the Cannizzaro reaction). ${ }^{7}$ The reaction of $\mathrm{Cu}^{2+}$ reduction in alkaline condition requires ethylenediaminetetraacetic acid (EDTA) as a complexing agent in order to prevent the precipitation of copper hydroxide, ${ }^{8}$ and the overall reaction can be written as: ${ }^{9}$

$$
\begin{aligned}
\mathrm{CuEDTA}^{2-}+2 \mathrm{HCHO}+4 \mathrm{OH}^{-} & \rightarrow \mathrm{Cu}^{0}+\mathrm{H}_{2}+2 \mathrm{H}_{2} \mathrm{O} \\
& +2 \mathrm{HCOO}^{-}+\mathrm{EDTA}^{4-}
\end{aligned}
$$

The synthesized particles are usually analysed via TEM, ${ }^{10-17}$ dynamic light scattering (DLS), ${ }^{18,19} \mathrm{X}$-ray diffractometry, ${ }^{20,21}$ IR or UV-Vis spectroscopy, ${ }^{22-25}$ electrophoretic light scattering (ELS), ${ }^{26,27}$ and so forth. TEM is the most widely used tool for the observation of the size, shape, and crystal structure of nanoparticle. However, the extremely high spatial resolution of TEM analysis sometimes causes difficulties in examining all particles, and therefore, it is often supported by other methods. In this study, we evaluated the gravimetric method for particle analysis. The gravimetric method is one of the oldest and simplest analytical methods, as it can be applied to any reaction system, regardless of the scale and uniformity. ${ }^{28}$ Gravimetric analysis does not require a sampling step, so that the change in the mass of particles would directly provide the information about the averaged growth of particle. However, the sensitivity of the gravimetric analysis is often limited by the mass resolution of the weighing scale, which is about $\left(10^{-3}\right.$ to $\left.10^{-5}\right) \mathrm{g}$ for a high precision balance. Subsequently, gravimetric analyses of the nanoparticles and their nucleation would be unreasonable,
1, Gwanak-gu, Seoul 08826, Republic of Korea. E-mail: ijkimm@snu.ac.kr

${ }^{b}$ School of Chemical Engineering, Kumoh National Institute of Technology, 61 Daehakro, Gumi, Gyeongbuk, 39177, Republic of Korea.E-mail: chosk@kumoh.ac.kr ${ }^{c}$ School of Chemical and Biological Engineering, Institute of Chemical Process, Seoul National University, Gwanak-ro 1, Gwanak-gu, Seoul, 08826, Korea

$\dagger$ Electronic supplementary information (ESI) available. See DOI: 10.1039/c9ra06842b 
but analyses of particles grown to the micrometer scale would have useful information about the particle growth.

In this research, we observed the formation of $\mathrm{Cu}$ microparticles through the gravimetric method. During particle synthesis, gradual increase in the total mass of $\mathrm{Cu}$ microparticles over time is anticipated and it is associated with nucleation, followed by surface growth. The increase would quickly be accelerated, due to the enlarged surface area of the growing particle with the heterogeneous autocatalytic $\mathrm{Cu}^{2+}$ reduction. ${ }^{29}$ Afterward, it would be quickly retarded, due to the depletion of $\mathrm{Cu}^{2+}$ in the solution. Consequently, the plot of mass against time would have a sigmoidal shape. In this study, the mass-time curve was simulated using pseudo- $1^{\text {st }}$ order autocatalytic surface reaction kinetics for $\mathrm{Cu}^{2+}$ reduction, and fitted to the experimental data. Consequently, the activation barrier energy for the autocatalytic growth of Cu microparticles was estimated from the simulated and fitted mass-time curve.

\section{Experimental}

\subsection{Chemicals}

Copper(II) sulfate pentahydrate $\left(\mathrm{CuSO}_{4} \cdot 5 \mathrm{H}_{2} \mathrm{O}\right.$, ACS Reagent), cobalt(II) sulfate heptahydrate $\left(\mathrm{CoSO}_{4} \cdot 7 \mathrm{H}_{2} \mathrm{O}\right.$, Reagent-plus), citric acid $\left(\mathrm{HOC}(\mathrm{COOH})\left(\mathrm{CH}_{2} \mathrm{COOH}\right)_{2}\right.$, ACS Reagent), potassium hydroxide (KOH, pellet type, ACS Reagent, 85\%), 2,2'dipyridyl $\left(\mathrm{C}_{10} \mathrm{H}_{8} \mathrm{~N}_{2}\right.$, Reagent-plus), hydrazine hydrate $\left(\mathrm{NH}_{2}{ }^{-}\right.$ $\mathrm{NH}_{2} \cdot \mathrm{H}_{2} \mathrm{O}$, Reagent grade, containing $64-65 \% \mathrm{~N}_{2} \mathrm{H}_{4}$ ), formaldehyde solution (HCHO, ACS Reagent, $37 \mathrm{wt} \%$ in $\mathrm{H}_{2} \mathrm{O}$, containing $10-15 \%$ methanol), sulfuric acid solution $\left(\mathrm{H}_{2} \mathrm{SO}_{4}\right.$, 95\%), and hydrogen peroxide (30 vol\%, ACS Reagent) were purchased from sigma Aldrich. EDTA $\left(\left(\mathrm{HO}_{2} \mathrm{CCH}_{2}\right)_{2}-\right.$ $\mathrm{NCH}_{2} \mathrm{CH}_{2} \mathrm{~N}\left(\mathrm{CH}_{2} \mathrm{CO}_{2} \mathrm{H}\right)_{2}$, ACS Reagent) was purchased from Junsei. All reagents were used without further purification.

\subsection{Particle synthesis and gravimetric measurement}

$\mathrm{Cu}$ particles were synthesized in aqueous solution $(100 \mathrm{~mL}$ as a reaction volume) containing $50 \mathrm{mM}$ of $\mathrm{CuSO}_{4} \cdot 5 \mathrm{H}_{2} \mathrm{O}, 100 \mathrm{mM}$ of EDTA, $150 \mathrm{mM}$ of $\mathrm{HCHO}$ and $600 \mathrm{mM}$ of KOH. If necessary, 1 $\mu \mathrm{M}$ of $2,2^{\prime}$-dipyridyl was added. ${ }^{30}$ The measurement started by injecting $\mathrm{HCHO}$ into the preheated $\mathrm{HCHO}$-free solution. Co particle was synthesized in $50 \mathrm{mM}$ of $\mathrm{CoSO}_{4} \cdot 7 \mathrm{H}_{2} \mathrm{O}, 300 \mathrm{mM}$ of citric acid, and $10 \mathrm{M}$ of $\mathrm{KOH}$ in $100 \mathrm{~mL}$ solution. The solution was pre-heated to $80^{\circ} \mathrm{C}$, and after that, hydrazine was added to form $600 \mathrm{mM}$ in the whole solution.

Synthesized particles were collected for weighing by filtering the solution using filter paper (200 $\mathrm{nm}$ pore size). Each experiment was repeated over 3 times, and the measured mass was averaged.

\subsection{Cu film growth}

The reaction rate of $\mathrm{Cu}^{2+}$ reduction was also estimated from the growth of $\mathrm{Cu}$ film on $\mathrm{Cu}$ foil $(0.8 \mathrm{~cm} \times 1.0 \mathrm{~cm}$, which area was similar to the total surface area of the synthesized particle) as the substrate. $\mathrm{Cu}$ foil was pretreated in order to remove the surface oxide by dipping in $10 \mathrm{vol} \% \mathrm{H}_{2} \mathrm{SO}_{4}$ and $3 \mathrm{vol} \%$ of $\mathrm{H}_{2} \mathrm{O}_{2}$ solution for $2 \mathrm{~min}$, followed by rinsing with deionized water for
$10 \mathrm{~s}$. All solutions were maintained at $25^{\circ} \mathrm{C}$. The pretreated $\mathrm{Cu}$ foil was dipped into the solution that was the same as the one used for particle synthesis, and its mass change was measured to estimate the amount of $\mathrm{Cu}$ film grown. In order to eliminate the effect of mass transfer of $\mathrm{Cu}^{2+}$, the solution was vigorously stirred during film growth.

\subsection{Particle analysis}

The shape and size of particles were evaluated using field emission scanning electron microscopy (FESEM, HITACHI S4800). X-ray diffraction (XRD, D8-Advanced, $\mathrm{Cu} \mathrm{K \alpha}$ radiation) patterns were obtained from $\mathrm{Cu}$ microparticles. The nonlinear least squares method was used for data fitting.

\section{Results and discussion}

Many studies have tried to demonstrate and simulate the sigmoidal curve for particle formation; the Smoluchowski rate equation $^{31,32}$ based on the collision of particles form a statistical perspective, the Kolmogorov-Johnson-Mehl-Avrami expression, ${ }^{33}$ for the solid-state phase transformation, the LifshitzSlyozov-Wagner model ${ }^{34}$ for Ostwald ripening and the relevant diffusion controlled growth model, ${ }^{16,35}$ and the Finke-Watzky $(\mathrm{F}-\mathrm{W})^{36}$ model, for fast autocatalytic surface growth. Since the growth of $\mathrm{Cu}$ microparticles has autocatalytic reaction characteristics, the model for the total mass as a function of time in this study is based on the F-W model under the assumption of the pseudo-elementary nucleation and growth steps, and it is expressed as: ${ }^{37}$

$$
\frac{\mathrm{d}[\mathrm{Cu}]}{\mathrm{d} t}\left(\mathrm{~mol} \mathrm{~cm}^{-3} \mathrm{~s}^{-1}\right)=k_{\mathrm{n}}\left[\mathrm{Cu}^{2+}\right]+k_{\mathrm{g}}\left[\mathrm{Cu}^{2+}\right][\mathrm{Cu}]
$$

where $\left[\mathrm{Cu}^{2+}\right]$ is the concentration of $\mathrm{Cu}^{2+}$ reactant, $[\mathrm{Cu}]$ is the molar amount of $\mathrm{Cu}$ per unit reaction volume, and $k_{\mathrm{n}}$ and $k_{\mathrm{g}}$ are the rate constants for nucleation and growth, respectively. The assumption of pseudo-elementary $\mathrm{Cu}$ growth in this study is quite as, and was confirmed by the reaction of $\mathrm{Cu}$ film growth on $\mathrm{Cu}$ foil which is a first order in $\mathrm{Cu}^{2+}$ (Fig. S1 of the ESI†). The multiplication of $[\mathrm{Cu}]$ in the second term on the right side of eqn (2) is the contribution of product to the autocatalytic reaction. In contrast to the homogeneous reaction, the contribution might not be linearly proportional to [Cu]. In the F-W model, it has been considered as a "scaling factor", which is the fraction of active surface ${ }^{38}$ atoms gained in the growth step. ${ }^{37}$ For particles of micrometer-sized scale, there would be plenty of active sites, which number is proportional to the surface area of microparticles. Accordingly, the contribution of $\mathrm{Cu}$ to the autocatalytic reaction might be proportional to $[\mathrm{Cu}]^{2 / 3}$, rather than $[\mathrm{Cu}]$.

Along with this consideration, eqn (2) can be transformed in terms of mass $\left(m=M_{\mathrm{w}}[\mathrm{Cu}]\right.$, where $m$ is the total mass of $\mathrm{Cu}$ particles per unit reaction volume, and $M_{\mathrm{w}}$ is the molar mass of $\mathrm{Cu}$ and it is $63.55 \mathrm{~g} \mathrm{~mol}^{-1}$ ) as follows (see the ESI†)

$$
\frac{\mathrm{d}}{\mathrm{d} t}\left(\frac{m}{m_{\mathrm{f}}}\right)=k_{\mathrm{n}}\left(1-\frac{m}{m_{\mathrm{f}}}\right)+k_{\mathrm{g}}\left(1-\frac{m}{m_{\mathrm{f}}}\right)\left(\frac{m}{m_{\mathrm{f}}}\right)^{2 / 3}
$$




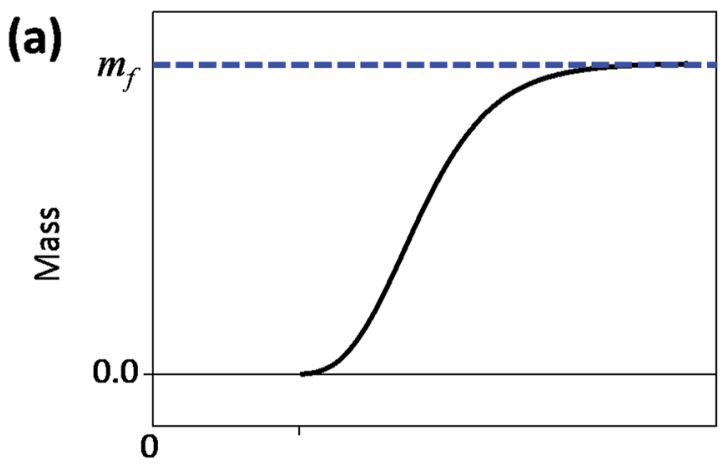

(b)

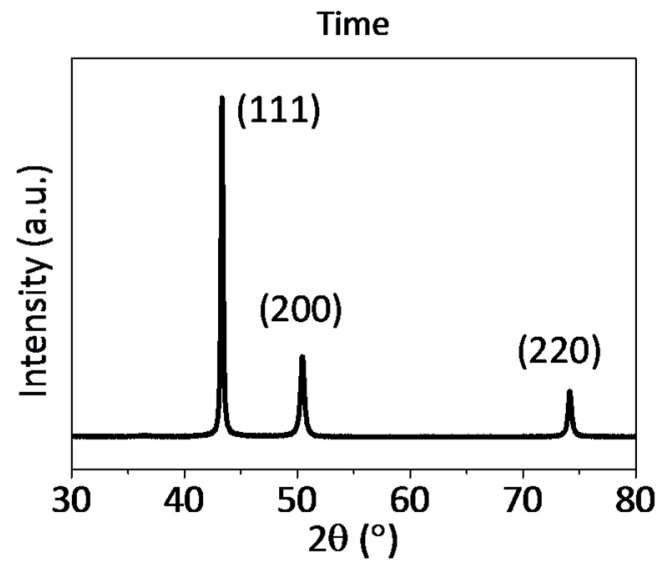

(c)

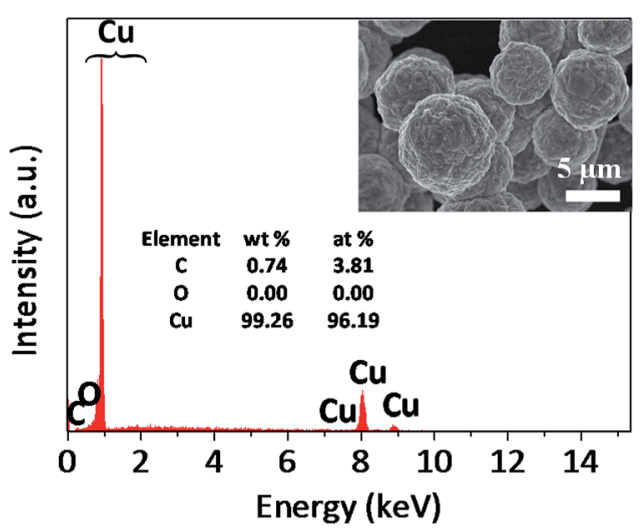

Fig. 1 (a) Theoretical sigmoidal curve of mass-time during the formation of microparticles, and (b) XRD data and (c) SEM-EDS result of the synthesized Cu microparticles. where $m_{\mathrm{f}}$ is the total mass of $\mathrm{Cu}$ particles per unit reaction volume when the reaction is completed and it is equal to $M_{\mathrm{w}}\left[\mathrm{Cu}^{2+}\right]_{0}\left(\left[\mathrm{Cu}^{2+}\right]_{0}\right.$ : the initial concentration of $\mathrm{Cu}^{2+},\left[\mathrm{Cu}^{2+}\right]_{0}=$ $\left.\left[\mathrm{Cu}^{2+}\right]+[\mathrm{Cu}]\right) \cdot\left(\mathrm{m} / \mathrm{m}_{\mathrm{f}}\right)^{2 / 3}$ presents a scaling factor in this study. Eqn (3) does not consider the mass transfer of $\mathrm{Cu}^{2+}$ to the $\mathrm{Cu}$ particle surface, since the autocatalytic surface growth step is normally not diffusion limited, ${ }^{37}$ and its effect is also minimized with the vigorous stirring during particle growth.

Consequently, the change in the total mass of $\mathrm{Cu}$ microparticles according to time can be expressed as an analytical solution of eqn (3) (see the ESI $\uparrow$ for details):

$$
\begin{aligned}
t= & \frac{1}{2\left(k_{\mathrm{g}}{ }^{3}+k_{\mathrm{n}}^{3}\right)}\left[\left(k_{\mathrm{g}}-2 k_{\mathrm{n}}\right)\left(k_{\mathrm{g}}+k_{\mathrm{n}}\right) \ln \left(1-\frac{m}{m_{\mathrm{f}}}\right)\right. \\
& -3 k_{\mathrm{g}}\left(k_{\mathrm{g}}-k_{\mathrm{n}}\right) \ln \left\{1-\left(\frac{m}{m_{\mathrm{f}}}\right)^{\frac{1}{3}}\right\} \\
& -6 k_{\mathrm{g}} \sqrt{k_{\mathrm{g}} k_{\mathrm{n}}} \tan ^{-1}\left\{\sqrt{\frac{k_{\mathrm{g}}}{k_{\mathrm{n}}}}\left(\frac{m}{m_{\mathrm{f}}}\right)^{\frac{1}{3}}\right\}+3{k_{\mathrm{n}}}^{2} \ln \left\{\frac{k_{\mathrm{g}}}{k_{\mathrm{n}}}\left(\frac{m}{m_{\mathrm{f}}}\right)^{\frac{2}{3}}+1\right\} \\
& \left.+2 \sqrt{3} k_{\mathrm{g}}\left(k_{\mathrm{g}}+k_{\mathrm{n}}\right)\left\{\tan ^{-1}\left(\frac{2}{\sqrt{3}}\left(\frac{m}{m_{\mathrm{f}}}\right)^{\frac{1}{3}}+\frac{1}{\sqrt{3}}\right)-\frac{\pi}{6}\right\}\right]
\end{aligned}
$$

The theoretical curve from eqn (4) has a sigmoidal shape, as expected (Fig. 1a). Fig. 1b and c shows that the synthesized particle is spherical, micrometer-sized, and a polycrystalline $\mathrm{Cu}$. The synthesized particles did not contain oxygen (Fig. 1c), which indicates that the $\mathrm{Cu}$ particle grows via the surface autocatalytic reduction of $\mathrm{Cu}^{2+}$ without other chemical reactions involved. ${ }^{39}$

Fig. 2a plots the total mass of $\mathrm{Cu}$ particles synthesized over time for various solution temperatures. In all reaction temperatures, the total mass increased with the sigmoidal shape and approached $m_{\mathrm{f}}$. At higher temperature, the mass of $\mathrm{Cu}$ particles was detected sooner and increased more abruptly. A fit of eqn (4) to the experimental data gives the values of various parameters such as $k_{\mathrm{g}}$, and $k_{\mathrm{n}}$, listed in Table 1 . As expected, the values of $k_{\mathrm{g}}$ and $k_{\mathrm{n}}$ increased with the reaction temperature. It is noticeable that $k_{\mathrm{g}}$ is much bigger than $k_{\mathrm{n}}$, and therefore, the (a)

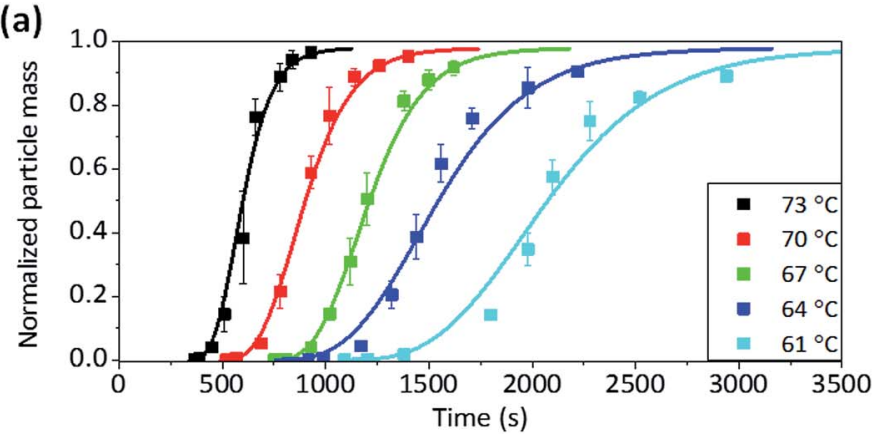

(b)

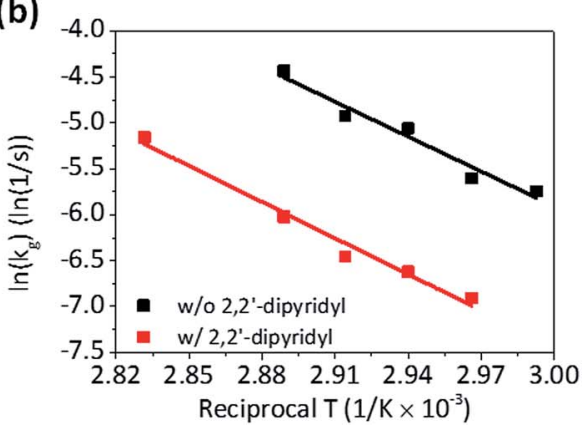

Fig. 2 (a) The plots of mass against time for the formation of Cu microparticles under various temperatures and fitted curves according to eqn (4), and (b) Arrhenius plots of the reaction constants $\left(k_{\mathrm{g}}\right)$ for the autocatalytic surface reaction, which were obtained from curve fitting. 
Table 1 List of curve fit values of $k_{\mathrm{g}}$ and $k_{\mathrm{n}}$ for the formation of $\mathrm{Cu}$ microparticle

\begin{tabular}{lcll}
$\begin{array}{l}\text { Temperature } \\
\left({ }^{\circ} \mathrm{C}\right)\end{array}$ & $k_{\mathrm{g}}\left(\mathrm{s}^{-1}\right) \times 10^{-3}$ & $k_{\mathrm{n}}\left(\mathrm{s}^{-1}\right) \times 10^{-10}$ & $t_{\text {ind }}(\mathrm{s})$ \\
\hline 73 & 11.8 & 9.95 & 365 \\
70 & 7.28 & 4.96 & 505 \\
67 & 6.35 & 2.23 & 753 \\
64 & 3.69 & 2.01 & 839 \\
61 & 3.21 & 1.16 & 1120
\end{tabular}

contribution of the second term on the right side of eqn (3) is much more significant than that of the first term for the mass increase, except when $m \ll m_{\mathrm{f}}$. This is consistent with the condition for the F-W model, which is "slow nucleation". ${ }^{37}$ It is also supported by the observation of Fig. S2 of the ESI, $\dagger$ which shows that the size of each particle increases without significant increase in the population as the reaction time passes. The Arrhenius plot of $k_{\mathrm{g}}$ shows that, the activation energy $\left(E_{\mathrm{a}}\right)$ for the autocatalytic growth reaction is about $105.4 \mathrm{~kJ} \mathrm{~mol}^{-1}$ (Fig. 2b).

The Arrhenius plot of Fig. $2 \mathrm{~b}$ shows the change in $E_{\mathrm{a}}$ that was observed with the addition of 2,2'-dipyridyl. The gravimetric analyses revealed that the increase in the mass was retarded, and $k_{\mathrm{g}}$ was reduced to one-tenth with the addition of $2,2^{\prime}$ dipyridyl (Fig. S3 of the ESI $\dagger$ ). $E_{\text {a }}$ was estimated to be $113.9 \mathrm{~kJ} \mathrm{~mol}^{-1}$, which is $8.5 \mathrm{~kJ} \mathrm{~mol}^{-1}$ larger than that without $2,2^{\prime}$-dipyridyl. It is reported that $2,2^{\prime}$-dipyridyl decreases the reaction rate of $\mathrm{Cu}^{2+}$ reduction via the adsorption on the $\mathrm{Cu}$ surface. ${ }^{40-42}$ The contribution of $8.5 \mathrm{~kJ} \mathrm{~mol}^{-1}$ to $k_{\mathrm{g}}$ is about $33 \%$ decrease in the reaction rate, indicating that the adsorbed $2,2^{\prime}$ dipyridyl on $\mathrm{Cu}$ also affect the pre-exponential factor that contains the collision rate of $\mathrm{Cu}^{2+}$ on the $\mathrm{Cu}$ surface and a steric factor (proper orientation of the collision for the reaction).

The validity of $E_{\mathrm{a}}$ was examined by comparison with the $E_{\mathrm{a}}$ value obtained from the film growth reaction on $\mathrm{Cu}$ foil (Fig. 3). For the $\mathrm{Cu}$ film growth on $\mathrm{Cu}$, the growth rate is generally expressed in a similar way to eqn (3) and is roughly treated as the absence of nucleation and a scaling factor. However, as it is a pseudo-first order heterogeneous surface reaction, its rate constant has a unit of $\left[\mathrm{cm} \mathrm{s}^{-1}\right]$. Accordingly, it is not appropriate to directly compare with $k_{\mathrm{g}}$. Nevertheless, the growth of microparticle and film would have same energetic state and the reaction pathway, and therefore, $E_{\mathrm{a}}$ for both reactions would also be identical. The growth rate of $\mathrm{Cu}$ film was measured in various temperatures (Fig. 3a), and Fig. 3b shows the Arrhenius plot of the rate constant. The obtained $E_{\mathrm{a}}$ of $\mathrm{Cu}$ film growth on $\mathrm{Cu}$ foil was about $104.0 \mathrm{~kJ} \mathrm{~mol}^{-1}$, which value was similar to the values from previous researches., ${ }^{5,9}$ The $E_{\mathrm{a}}$ values estimated from both the gravimetric method and the film growth are almost identical, indicating that the model used in this study interprets the autocatalytic growth kinetics of $\mathrm{Cu}$ microparticles well.

Consideration of the scaling factor $\left(\mathrm{m} / \mathrm{m}_{\mathrm{f}}\right)^{2 / 3}$ was found to be important for the precise estimation of $k_{\mathrm{g}}$ and $E_{\mathrm{a}}$. If the experimental results are fitted to the simple $\mathrm{F}-\mathrm{W}$ model that is based on eqn (2) without the consideration of the scale factor, $E_{\mathrm{a}}$ is obtained as $137.7 \mathrm{~kJ} \mathrm{~mol}^{-1}$ which shows a relatively large difference from the one from the film growth (Fig. S4 of the $\mathrm{ESI} \dagger$ ).

The validity of this model was not limited to the synthesis of $\mathrm{Cu}$ microparticles. It could also be successfully applied to the synthesis of Co spherical particles, which is an another example of the autocatalytic reaction. ${ }^{43}$ The sigmoidal curve of the total amount of Co particle over time was obtained by the gravimetric method (Fig. 4) and its kinetic parameters could be evaluated (Table 2).

The curve fitting also provides the information of $k_{\mathrm{n}}$, and in this study, its change was observed with the addition of $2,2^{\prime}$ dipyridyl. Unfortunately, the $k_{\mathrm{n}}$ values were extremely small, and varied significantly with the mass measured at the early stage of the particle synthesis. This might be associated with the mass resolution limit in this study, and it indicates that the kinetic information on the nucleation step might be beyond the capability of gravimetric analysis. The nucleation step is critical for the control of the morphology or dimension of the synthesized particle, ${ }^{\mathbf{4 4 , 4 5}}$ and it is also closely related to scaling factor in this kinetic model. Therefore, our future study would focus on the gravimetric analysis on $\mathrm{Cu}$ particle with various shapes other than the sphere, synthesized by using an adequate capping agents such as ethylenediamine ${ }^{46}$ or cetyltrimethylammonium bromide. ${ }^{47}$
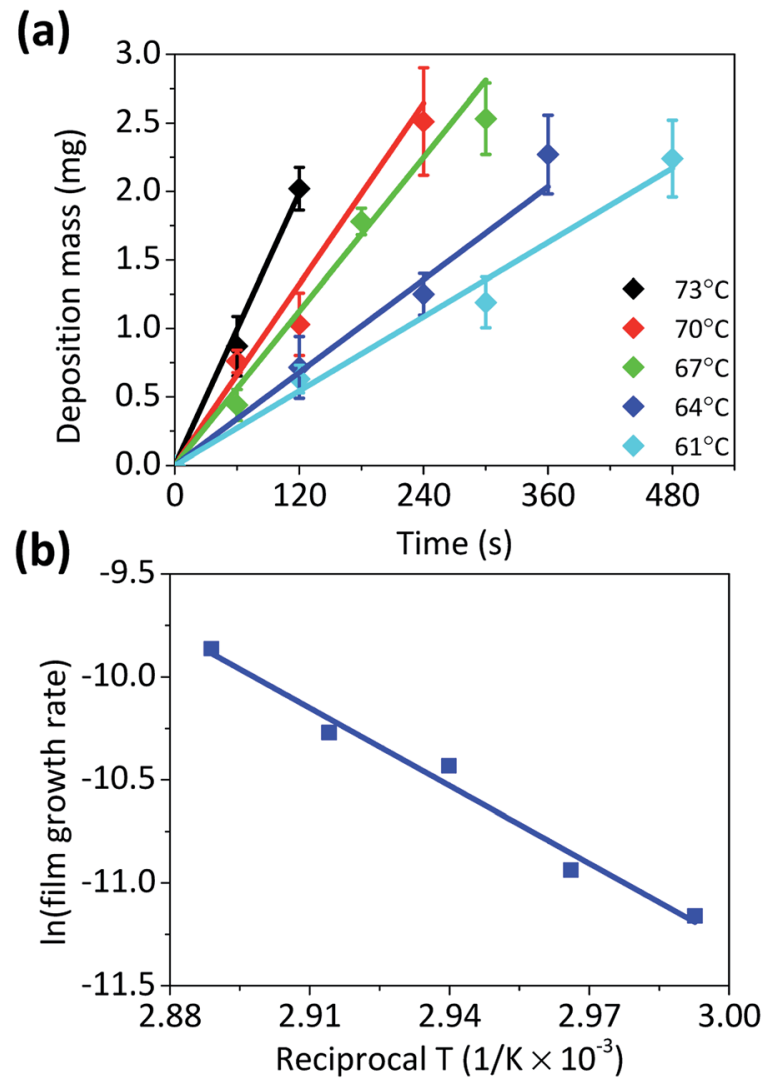

Fig. 3 (a) The plots of mass against time for the formation of Cu films under various temperatures and (b) the Arrhenius plot of the reaction constants for $\mathrm{Cu}$ film growth. The activation energy was calculated as $104.0 \mathrm{~kJ} \mathrm{~mol}^{-1}$. 
(a)

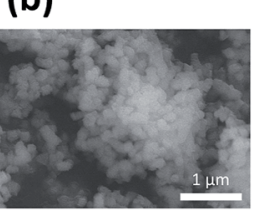
$290 \mathrm{~nm}$

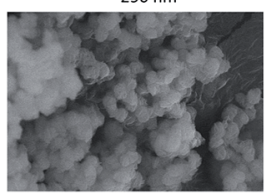

$400 \mathrm{~nm}$

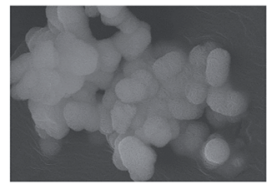

$803 \mathrm{~nm}$

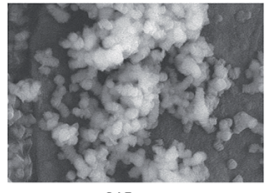
$315 \mathrm{~nm}$

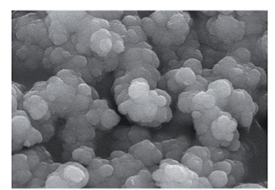

$520 \mathrm{~nm}$

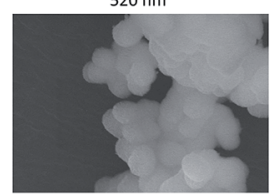

$817 \mathrm{~nm}$

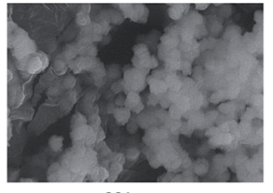

$381 \mathrm{~nm}$

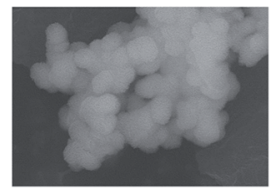

$700 \mathrm{~nm}$

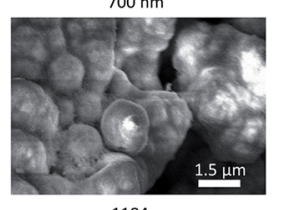

$1184 \mathrm{~nm}$

Fig. 4 (a) The plots of mass against time for the formation of Co microparticles, and (b) FESEM images of the synthesized Co microparticles. The number at the bottom of each figure corresponds to the average size of Co microparticle.

Table 2 List of curve fit values of $k_{\mathrm{g}}$ and $k_{\mathrm{n}}$ for the formation of Co microparticle

\begin{tabular}{ll}
\hline Fitting parameters & Value \\
\hline$k_{\mathrm{g}}\left(\mathrm{s}^{-1}\right) \times 10^{-4}$ & 1.37 \\
$k_{\mathrm{n}}\left(\mathrm{s}^{-1}\right) \times 10^{-12}$ & 9.55 \\
$t_{\text {ind }}(\mathrm{s})$ & 8000
\end{tabular}

\section{Conclusions}

We derived the theoretical relation between the total mass of the $\mathrm{Cu}$ microparticle and the reaction time, which contained $k_{\mathrm{n}}$ and $k_{\mathrm{g}}$, with the modification of the $\mathrm{F}-\mathrm{W}$ autocatalytic growth model. This was verified by gravimetric analysis of the formation of $\mathrm{Cu}$ microparticles. The sigmoidal curve-to-fit provides $k_{\mathrm{g}}$ for the autocatalytic surface growth of $\mathrm{Cu}$ microparticles. From its Arrhenius plot analysis, $E_{\mathrm{a}}$ for the surface growth was estimated to be $105.4 \mathrm{~kJ} \mathrm{~mol}^{-1}$, and which is almost identical to the value from the film growth $\left(104.0 \mathrm{~kJ} \mathrm{~mol}^{-1}\right)$. The introduction of the scaling factor $\left(\mathrm{m} / \mathrm{m}_{\mathrm{f}}\right)^{2 / 3}$ into the rate equation was critical for the precise estimation of $E_{\mathrm{a}}$, and the model used in this study

could be also applied to the investigation of Co particle growth. The change in the growth rate of $\mathrm{Cu}$ particle with the addition of 2,2 '-dipyridyl was clearly manifested in the gravimetric analysis and it was associated with the decrease in $k_{\mathrm{g}}$.

\section{Conflicts of interest}

There are no conflicts to declare.

\section{Acknowledgements}

This work was supported by the National Research Foundation of Korea (NRF) grant funded by the Korea government (MSIT) (No. NRF-2019R1F1A1063658 and No. NRF-2019R1A2C1002400).

\section{Notes and references}

1 C. Murray, D. J. Norris and M. G. Bawendi, J. Am. Chem. Soc., 1993, 115, 8706-8715.

2 V. K. LaMer, Ind. Eng. Chem., 1952, 44, 1270-1277.

3 L. R. Houk, S. R. Challa, B. Grayson, P. Fanson and A. K. Datye, Langmuir, 2009, 25, 11225-11227.

4 F. Wang, V. N. Richards, S. P. Shields and W. E. Buhro, Chem. Mater., 2014, 26, 5-21.

5 R. Schumacher, J. Pesek and O. Melroy, J. Phys. Chem., 1985, 89, 4338-4342.

6 Y. Shacham-Diamand and V. M. Dubin, Microelectron. Eng., 1997, 33, 47-58.

7 R. Martin, Aust. J. Chem., 1954, 7, 335-347.

8 T. Lim, K. J. Park, M. J. Kim, H. C. Koo, K. H. Kim, S. Choe and J. J. Kim, J. Electrochem. Soc., 2013, 160, D3134-D3138.

9 Y. Shacham-Diamand, V. Dubin and M. Angyal, Thin Solid Films, 1995, 262, 93-103.

10 V. Richards, Doctor of Philosophy, Washington University, 2010.

11 V. N. Richards, S. P. Shields and W. E. Buhro, Chem. Mater., 2010, 23, 137-144.

12 S. P. Shields, V. N. Richards and W. E. Buhro, Chem. Mater., 2010, 22, 3212-3225.

13 V. N. Richards, N. P. Rath and W. E. Buhro, Chem. Mater., 2010, 22, 3556-3567.

14 J. Park, K. An, Y. Hwang, J. G. Park, H. J. Noh, J. Y. Kim, J. H. Park, N. M. Hwang and T. Hyeon, Nat. Mater., 2004, 3, 891-895.

15 J. Park, J. Joo, S. G. Kwon, Y. Jang and T. Hyeon, Angew. Chem., Int. Ed. Engl., 2007, 46, 4630-4660.

16 S. G. Kwon, Y. Piao, J. Park, S. Angappane, Y. Jo, N.-M. Hwang, J.-G. Park and T. Hyeon, J. Am. Chem. Soc., 2007, 129, 12571-12584.

17 S. G. Kwon and T. Hyeon, Small, 2011, 7, 2685-2702.

18 B. Krämer, O. Hübner, H. Vortisch, L. Wöste, T. Leisner, M. Schwell, E. Rühl and H. Baumgärtel, J. Chem. Phys., 1999, 111, 6521-6527.

19 R. Bar-Ziv, A. Meller, T. Tlusty, E. Moses, J. Stavans and S. Safran, Phys. Rev. Lett., 1997, 78, 154.

20 E. C. Vreeland, J. Watt, G. B. Schober, B. G. Hance, M. J. Austin, A. D. Price, B. D. Fellows, T. C. Monson, 
N. S. Hudak and L. Maldonado-Camargo, Chem. Mater., 2015, 27, 6059-6066.

21 J. Polte, T. T. Ahner, F. Delissen, S. Sokolov, F. Emmerling, A. F. Thuenemann and R. Kraehnert, J. Am. Chem. Soc., 2010, 132, 1296-1301.

22 A. V. Gaikwad and G. Rothenberg, Phys. Chem. Chem. Phys., 2006, 8, 3669-3675.

23 S. Ishizuka, Y. Kimura, T. Yamazaki, T. Hama, N. Watanabe and A. Kouchi, Chem. Mater., 2016, 28, 8732-8741.

24 B. Streszewski, W. Jaworski, K. Pacławski, E. Csapó, I. Dékány and K. Fitzner, Colloids Surf., A, 2012, 397, 63-72.

25 M. Harada and Y. Kamigaito, Langmuir, 2012, 28, 2415-2428.

26 C. A. Aerts, E. Verraedt, R. Mellaerts, A. Depla, P. Augustijns, J. Van Humbeeck, G. Van den Mooter and J. A. Martens, J. Phys. Chem. C, 2007, 111, 13404-13409.

27 K. J. Park, H.-C. Koo, T. Lim, M. J. Kim, O. J. Kwon and J. J. Kim, J. Electrochem. Soc., 2011, 158, D541.

28 D. C. Harris, Quantitative chemical analysis, Macmillan, 2010.

29 Y.-C. Zhu, Y. Bando and D.-F. Xue, Appl. Phys. Lett., 2003, 82, 1769-1771.

30 K. J. Park, M. J. Kim, T. Lim, H.-C. Koo and J. J. Kim, Electrochem. Solid-State Lett., 2012, 15, D26.

31 G. Bogush and C. Zukoski IV, J. Colloid Interface Sci., 1991, 142, 1-18.

32 J. Zhang, Z. Lin, Y. Lan, G. Ren, D. Chen, F. Huang and M. Hong, J. Am. Chem. Soc., 2006, 128, 12981-12987.

33 A. Burbelko, E. Fraś and W. Kapturkiewicz, Mater. Sci. Eng., A, 2005, 413, 429-434.
34 I. M. Lifshitz and V. V. Slyozov, J. Phys. Chem. Solids, 1961, 19, 35-50.

35 M. O. Besenhard, R. Baber, A. P. LaGrow, L. Mazzei, N. T. Thanh and A. Gavriilidis, CrystEngComm, 2018, 20, 7082-7093.

36 L. Bentea, M. A. Watzky and R. G. Finke, J. Phys. Chem. C, 2017, 121, 5302-5312.

37 M. Watzky and R. Finke, J. Am. Chem. Soc., 1997, 119, 1038210400.

38 T. Nguyen, R. Hammond, K. Roberts, I. Marziano and G. Nichols, CrystEngComm, 2014, 16, 4568-4586.

39 S. Ghosh, Thin Solid Films, 2018, 669, 641-658.

40 W. Chen, G. Luo, M. Li, Q. Shen, C. Wang and L. Zhang, Appl. Surf. Sci., 2014, 301, 85-90.

41 K. Kondo, K. Kojima, N. Ishida and M. Irie, J. Electrochem. Soc., 1993, 140, 1598-1601.

42 F. Fernandez-Palacio, M. Saccone, A. Priimagi, G. Terraneo, T. Pilati, P. Metrangolo and G. Resnati, CrystEngComm, 2016, 18, 2251-2257.

43 Y. Okinaka and T. Osaka, Electroless deposition processes: fundamentals and applications, 2008, pp. 55-116.

44 D. Huo, M. J. Kim, Z. Lyu, Y. Shi, B. J. Wiley and Y. Xia, Chem. Rev., 2019, 119, 8972-9073.

45 H. Brune, Surf. Sci. Rep., 1998, 31, 125-229.

46 M. J. Kim, P. F. Flowers, I. E. Stewart, S. Ye, S. Baek, J. J. Kim and B. J. Wiley, J. Am. Chem. Soc., 2016, 139, 277-284.

47 S.-H. Wu and D.-H. Chen, J. Colloid Interface Sci., 2004, 273, 165-169. 